\title{
Stability of black grass jelly (Mesona chinensis) probioticated by encapsulation of Lactobacillus plantarum Mar8 with agar and gum Arabic
}

\author{
NILAM FADMAULIDHA WULANDARI", TITIN YULINERY, NANDANG SUHARNA, NOVIK NURHIDAYAT \\ Microbiology Division, Research Center for Biology, Indonesian Institute of Sciences. Jl. Raya Jakarta Bogor Km 46, Cibinong, Bogor 16911, West \\ Java, Indonesia. Tel.: +62-21-87907604; 87907636, Fax.: +62-21-87907612, "email: nilamwulandari@ gmail.com.
}

Manuscript received: 29 December 2018. Revision accepted: 25 March 2019.

\begin{abstract}
Wulandari NF, Yulinery T, Suharna N, Nurhidayat N. 2019. Stability of black grass jelly (Mesona chinensis) probioticated by encapsulation of Lactobacillus plantarum Mar8 with agar and gum Arabic. Nusantara Bioscience 11: 84-88. Black grass jelly [Mesona chinensis (Benth)] is one of the traditional food ingredients that can be used as the encapsulation material. However, syneresis easily occurs so that becomes a problem during storage. This study was conducted to evaluate the effect of type of stabilizers (agar and gum Arabic) and storage temperature $\left(\operatorname{cold} / 4^{\circ} \mathrm{C}\right.$ and ambient temperature $\left./ 37^{\circ} \mathrm{C}\right)$ on black grass jelly stability and the viability of encapsulated Lactobacillus plantarum Mar8 in probiotication. The concentrations of stabilizers were $0.5 \% ; 1.0 \% ; 1.5 \%$ and $2.0 \%$ (w/v). The result showed that the syneresis rate was stable up to $2 \%$ of agar concentration at low storage temperature, while gum Arabic in the concentration of $>1 \%$ resulted in increasing syneresis rate. Ambient temperature storage increased the syneresis rate. This study showed that agar or gum Arabic was supporting the probiotication as good encapsulant. Moreover, it was suitable for stabilizing or gelling agent at $0.5 \%-1 \%$ concentration to produce black grass jelly as RTD.
\end{abstract}

Keywords: Black grass jelly, probiotic, storage, syneresis

\section{INTRODUCTION}

The term probiotics are technically defined as living microorganisms which after being consumed in certain quantities provide health benefits beyond inherent general nutrition (FAO/WHO 2002; Mustafa 2016; Seddik et al. 2017). Guidelines for evaluating probiotics in food compiled by the Joint Food and Agriculture Organization/ World Health Organization (FAO/WHO) define the term probiotics as "living microorganisms that, when given in sufficient quantities, provide health benefits" (FAO/WHO 2002). This guide evaluates prospective probiotics with in vitro tests including resistance to acidity, bile acid resistance, adherence to mucus and/or human epithelial cells and cell lines, anti-microbial activity against pathogenic bacteria, ability to reduce pathogenic adhesion to the surface, hydrolase salt activity bile, and resistance to spermicide. Probiotics are also usually characterized by traits such as acid resistance, tolerance to bile salts, antimicrobial activity, antibiotic resistance, intestinal epithelial cell adhesion, resistance to simulated gastricintestinal fluid and lysozyme (O'Hara and Shanahan 2006; Booijink et al. 2007). Lactobacillus plantarum Mar8 is one of the selected potential probiotics originated from tropical fruit, i.e., passion fruit (Passiflora edulis) (Nurhidayat 2012; Yulinery and Nurhidayat 2015). Previous study showed that this strain was able to produce plantaricin A (Yulinery and Nurhidayat 2015) and a stable mannosespecific adhesion (Nurhidayat 2012). Based on these properties, this strain was ideal as a probiotic for intestinal health.

Its application as a probiotic supplement on the black jelly is very interesting especially as a ready to drink (RTD). This is certainly closely related to the nature of black grass jelly which has an impact on health, especially if consumed daily. According to Handayani et al. (2017), this jelly was known as healthy food or drink because it contained high concentration of soluble fiber and lowcalorie. High soluble fiber had been proven to reduce lipid profiles (Ramos et al. 2011; Wahyono et al. 2015; Handayani et al. 2017). The Indonesian Ministry of Health's Nutrition Directorate (year of 1992) stated that 100 grams of black jelly contained 6.23 grams of crude fiber. Daily consumption of black jelly will be able to meet daily fiber requirements $(30 \mathrm{~g})$. Its high phenol content in black jelly might be related to high antioxidant activity, so that it might prevent DNA damage in human lymphocytes due to exposure to free radicals such as hydrogen peroxide and UV radiation (Tasia and Widyaningsih 2014; Handayani et al. 2017). In addition, black jelly was found to have anti-dyslipidemia activity in rats fed with high cholesterol (Handayani et al. 2017).

However, in the probiotication of black grass jelly drinks preconditions are needed to support the viability and stability of probiotics, including encapsulation. Encapsulation must be suitable to be applied to black grass jelly as an RTD. In a previous study, black grass jelly with a concentration of $4 \%$ had not been able to maintain viability or stability of $L$. plantarum, so that a suitable 
stabilizer was needed. In this study, commercial agar and gum Arabic were studied for their suitability for both as stabilizer and encapsulant for probiotic.

Gum Arabic is collected from the branches of acacia species and is usually used in the food industrial sector as a food additive (Bertolini et al. 2001; Motlagh et al. 2006). The gum originated from Acacia senegal is known as the foremost gum used for commercial purposes because it has boosted emulsification properties when linked to the gum collected from A. seyal (Elmanan et al. 2008). Gum Arabic use is been allowable as an unthreatened compound by the joint FAO/WHO Expert Committee on Food Additive (Anderson and Eastwood 1987). Gum Arabic is also known as a primary coating component owing to its emulsifying properties (Maqbool et al. 2011; Valiathan and Athmaselvi 2018).

The purpose of this study was to obtain a jelly stabilizer and its suitability for encapsulation of L. plantarum applied to black jelly drink as RTD.

\section{MATERIALS AND METHODS}

\section{Encapsulation of probiotic bacteria Cultivation}

One ose of L. plantarum Mar8 isolate from oblique agar media was inoculated in a $200 \mathrm{ml}$ sterile Lactobacillus MRS Broth media (Himedia RefM369-500g) and incubated for 24 hours. This culture was used as the master culture. $200 \mu \mathrm{L}$ of master culture were taken out and put into 200 $\mathrm{ml}$ of MRS broth media and incubated for 48 hours at $\left(37^{\circ} \mathrm{C}\right)$. This culture was prepared for pellet collection.

\section{Pellet collection}

The bacterial biomass was collected by centrifugation at $10,000 \mathrm{rpm}$ (revolutions per minute) for 15 minutes. The pellets were then collected.

\section{Jelly stabilization and probiotic encapsulation}

Four grams of jelly were mixed in $1 \mathrm{~L}$ of boiling water and stirred carefully. Each stabilizers (encapsulants) i.e.: commercial agar and gum Arabic at different concentrations $(0.5 \% ; 1 \% ; 1.5 \% ; 2 \%)$ were mixed with jelly by three replications. After reaching ambient temperature $\left(37^{\circ} \mathrm{C}\right), 1$ gram of the bacterial pellets was added to each jelly and mixed carefully. After being hardened $\left(25^{\circ} \mathrm{C}\right)$, each of the jelly mixtures was stored in 2 different storage temperature (ambient temperature $/ 37^{\circ} \mathrm{C}$ ) and cold temperature $/ 4^{\circ} \mathrm{C}$ ).

\section{Viability test after encapsulation}

The encapsulation products were stored in sterile container. After stabilization and encapsulation were complete, each mixture of black grass jelly containing stabilizer and probiotics were stored at ambient temperature $\left(37^{\circ} \mathrm{C}\right)$ and cold temperature $\left(4^{\circ} \mathrm{C}\right)$. The total plate count was performed in series dilutions of $10^{-4}, 10^{-5}$ and $10^{-6}$. Colony counting was carried out after $36-48$ hours of incubation period at ambient temperature and cold temperature.

\section{Physical and organoleptic analysis}

Syneresis and $\mathrm{pH}$ were measured at $37^{\circ} \mathrm{C}$ and $4{ }^{\circ} \mathrm{C}$. Syneresis was measured by calculating the weight loss during storage compared to the initial weight (Latimer, 2012). Flow rate, syneresis, texture, breaking strength were observed and measured directly at cold temperature $\left(4^{\circ} \mathrm{C}\right)$. Breaking strength was measured using the Lloyd instrument, $\mathrm{pH}$ was determined by $\mathrm{pH}$ meter.

\section{RESULTS AND DISCUSSION}

\section{Results}

The results showed that the rate of syneresis was lower at cold storage temperature $\left(4^{\circ} \mathrm{C}\right)$ compared to ambient temperature storage $\left(37^{\circ} \mathrm{C}\right)$. At ambient temperature storage $\left(37^{\circ} \mathrm{C}\right)$, the rate of syneresis was faster shown in the mixture with $2 \%$ gum Arabic than the mixture with agar. The syneresis rate at cold temperature storage $\left(4^{\circ} \mathrm{C}\right)$ was 37 and 30. 2 at the mixture of gum Arabic $0.5 \%$ and $1 \%$ respectively, but they were not statistically different. The syneresis rate in the mixture with gum Arabic at the concentration of 1.5 and $2 \%$ were almost in similar rate but increases twice when compared to the gum arabic mixture in concentrations of 0.5 and $1 \%$ (Figure 1).

The initial $\mathrm{pH}$ of all jelly mixtures before storage was 7 . However, storing the mixture at ambient temperature caused the $\mathrm{pH}$ decreased to 4 . While storing in cold temperature $\left(4^{\circ} \mathrm{C}\right)$, the $\mathrm{pH}$ of both jelly mixtures with agar or gum Arabic were stable at 7 (Table 1).

Flow rates at cold temperature storage in the mixture of $2 \%$ agar or $0.5 \%$ gum Arabic were similar to control. However, it increases in the mixture of agar at a concentration of $0.5,1$ and $1.5 \%$. Flow rate also increased very rapidly in the mixtures of gum Arabic at concentrations of $1.5 \%$ and $2 \%$ (Fig. 2).

Breaking strength of the mixture with 0.5 and $1 \%$ gum Arabic almost the same rate i.e.: 28.56 and 29.9 respectively, while breaking strength of controls were 29.31 and 29.78 points for agar and gum Arabic respectively. On the contrary, the mixture with $1.5 \%$ and $2 \%$ of gum Arabic decreased breaking strength to 24.04 and 19.04 respectively.

There were similarities in the texture of the mixture with agar and gum Arabic at concentrations of 0.5 and 1\%, respectively. However, the mixture with agar at the concentrations of 1.5 and $2 \%$ caused the jelly mixture to become harder. Texture of the mixture with gum Arabic at concentrations $>1.5 \%$ were soft and flabby (Table 1 ).

Both types of encapsulants or stabilizers could maintain the stability and high viability of probiotics. Viability of $L$. plantarum Mar8 was better in the agar mixture $\left(9.7 \times 10^{8}\right.$ $\mathrm{cfu} / \mathrm{mL})$ compared to the gum arabic mixture $\left(6.7 \times 10^{8}\right.$ $\mathrm{cfu} / \mathrm{mL})$ (Table 2).

\section{Discussion}

The results of this study indicated that the storage temperature had an effect on syneresis of the jelly that might also be related to the $\mathrm{pH}$ change of the jelly. The initial $\mathrm{pH}$ of all mixtures were 7 but it decreased after 
stored at ambient temperature $\left(37^{\circ} \mathrm{C}\right)$ to 4 . At this $\mathrm{pH}$ value, syneresis increases. This might be due to the low $\mathrm{pH}$ changing the chemical structures due to acidic conditions. Organic acids may react to the structure and chemical composition of the mixed mixture. Black jelly is known to contain organic acids which influence the decrease in $\mathrm{pH}$ (Yulianto and Widyaningsih 2013).

Jelly mixture with agar or gum Arabic had an impact on syneresis. The syneresis might lower if the concentration of agar or gum Arabic was higher. Gum Arabic at a concentration of $1.5 \%$ and $2 \%$ underwent a drastic change of its syneresis compared to $0.5 \%$ and $1 \%$.

The results of the measurement of "breaking strength", show that only by adding a $1 \%$ gum Arabic to the grass jelly were similar to that of control, it means that the addition of gum Arabic up to $1 \%$ has no effect. Whereas the addition of agar reduces "breaking strength" even though the concentration increases further. Conversely, the addition of gum Arabic above $1 \%$ resulted in decreasing breaking strength.

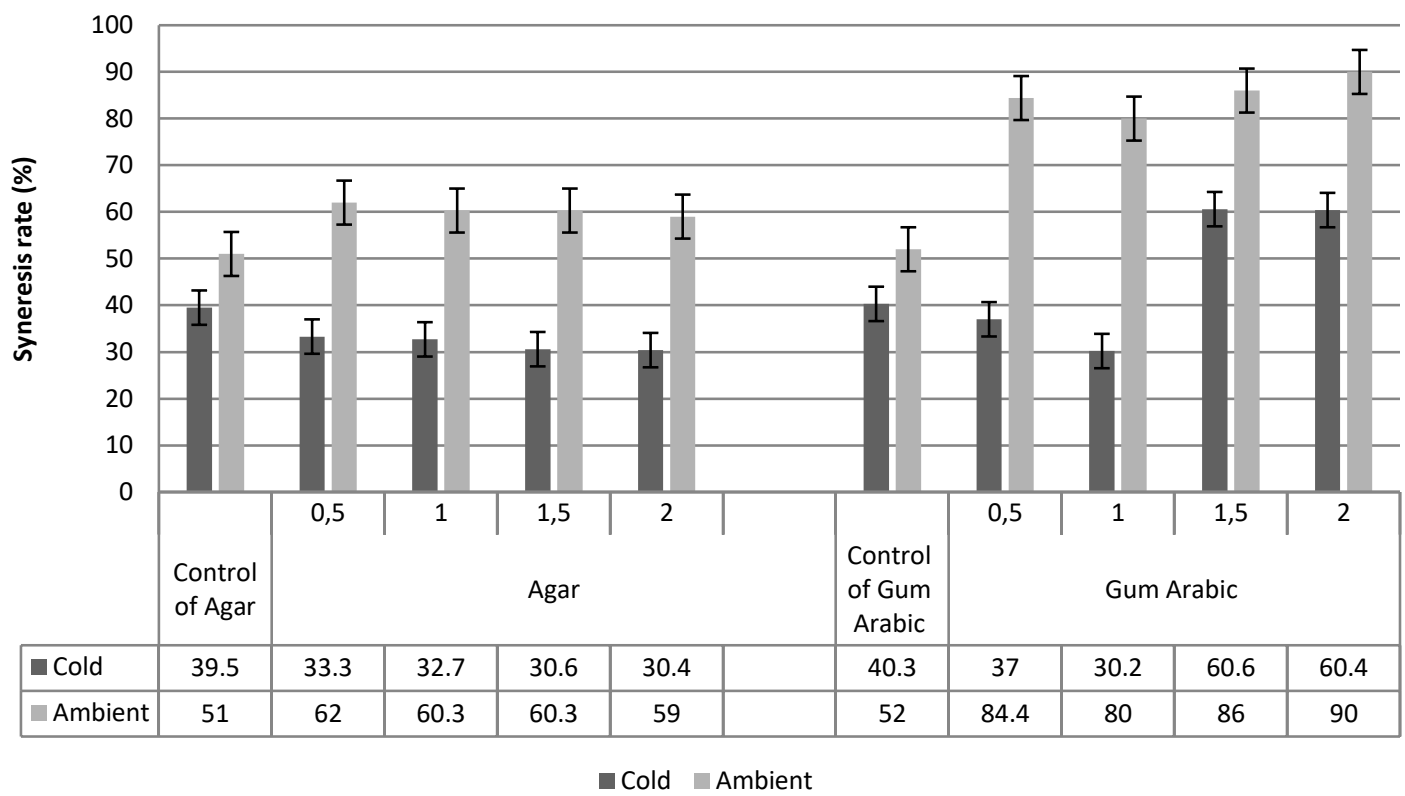

Figure 1. Syneresis rate (\%) of black grass jelly in mixture with Agar or gum Arabic at cold temperature storage $\left(4^{\circ} \mathrm{C}\right)$ and ambient temperature storage $\left(37^{\circ} \mathrm{C}\right)$ with 4 different concentrations of agar or gum Arabic $(0.5,1,1.5$ and $2 \%)$.

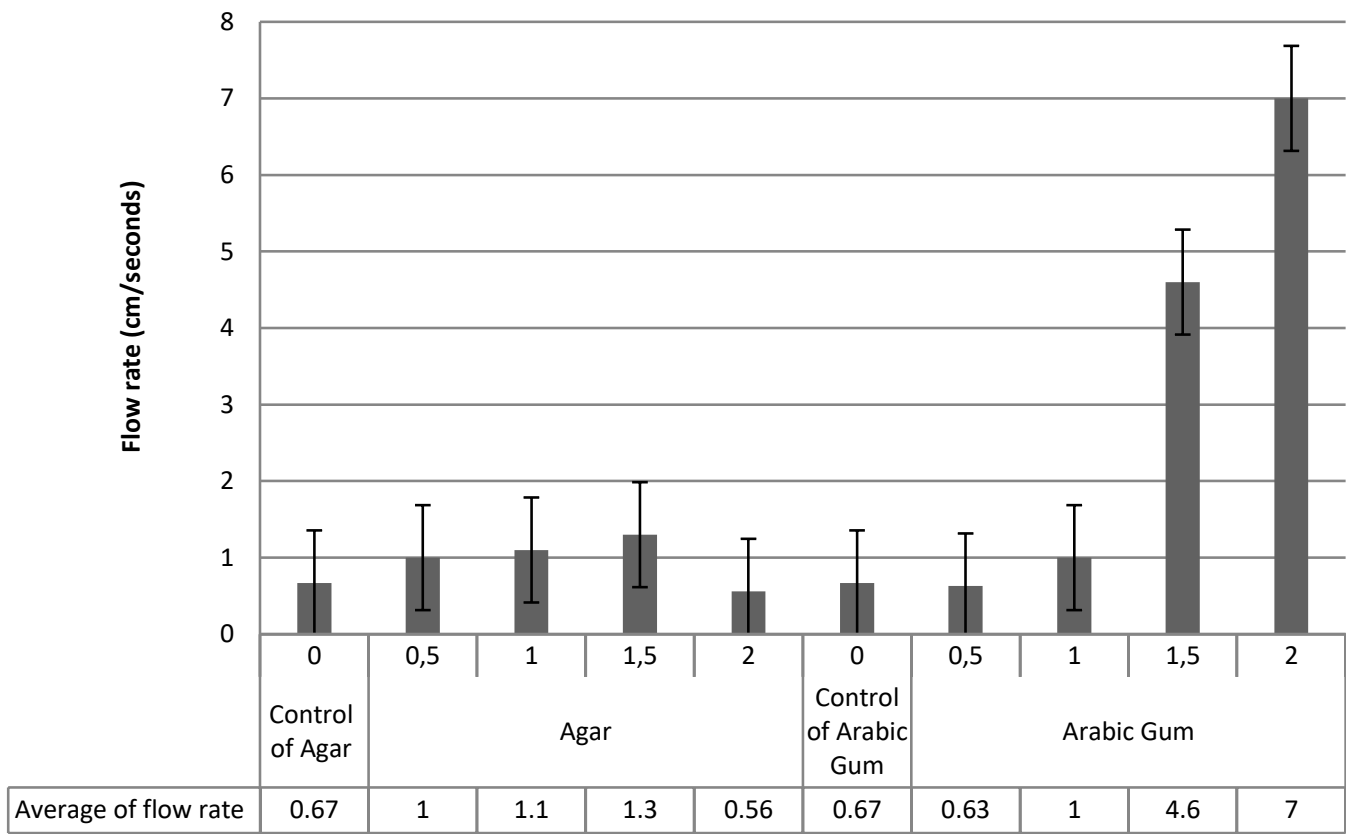

Figure 2. Flow rate of the jelly mixture with agar and gum Arabic at cold temperature. 


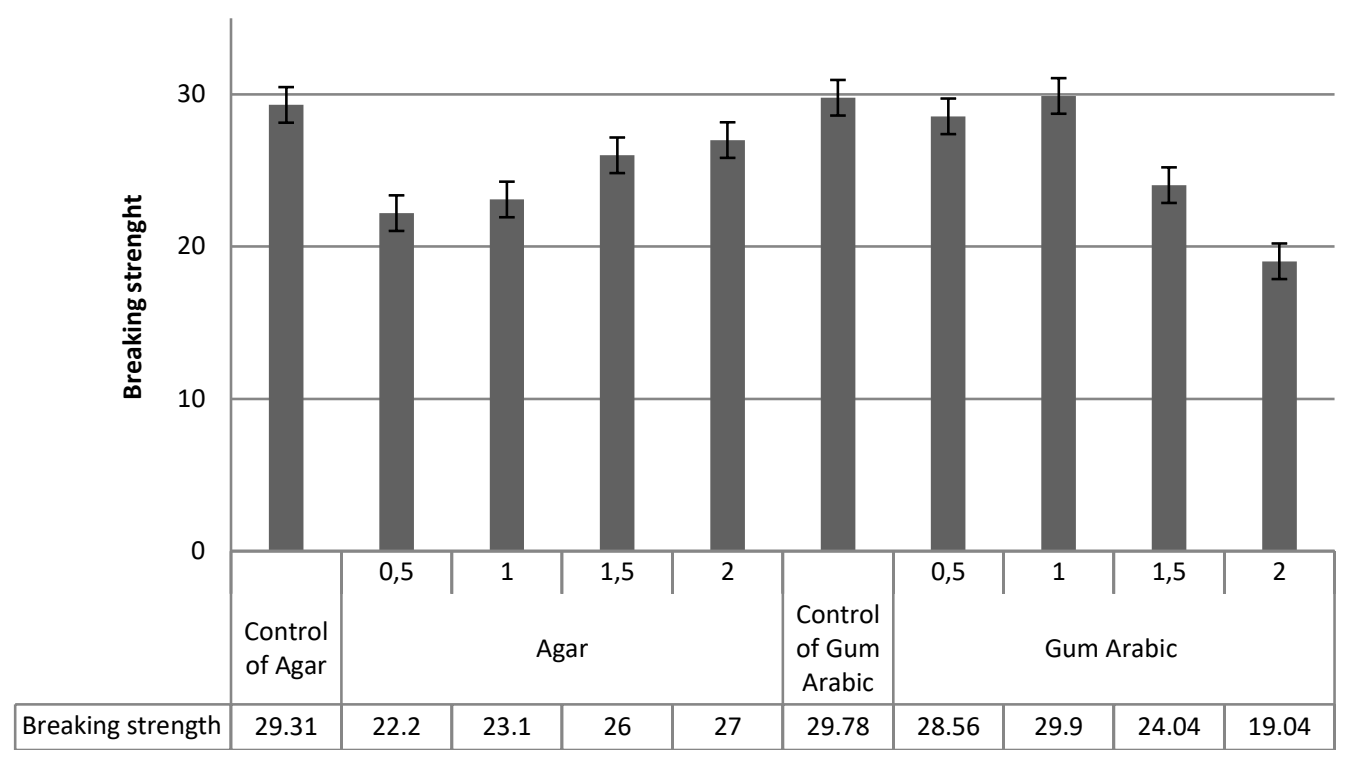

Figure 3. Breaking strength of jelly mixture with agar or gum Arabic with various concentrations stored at cold temperature

Table 1. The $\mathrm{pH}$ and texture of the jelly mixture with stabilizers.

\section{pH Texture

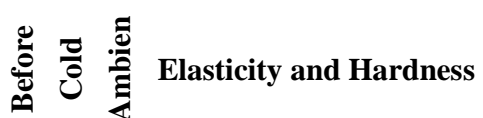

\begin{tabular}{lcccll}
\hline Control of agar & & 7 & 7 & 4 & \\
Agar & 0.5 & 7 & 7 & 4 & Chewy (+) \\
& 1 & 7 & 7 & 4 & Chewy (+) \\
& 1.5 & 7 & 7 & 4 & Chewy and rather hard (++) \\
& 2 & 7 & 7 & 4 & Chewy and rather hard (++) \\
Control of gum Arabic & 7 & 7 & 4 & \\
Gum Arabic & 0.5 & 7 & 7 & 4 & Chewy (+) \\
& 1 & 7 & 7 & 4 & Chewy (++) \\
& 1.5 & 7 & 7 & 4 & Soft and flabby (+) \\
& 2 & 7 & 7 & 4 & Soft and flabby (+++) \\
\hline
\end{tabular}

Table 2. Viability of Lactobacillus plantarum Mar8 in jelly mixture with encapsulants after stored for two weeks at $4^{\circ} \mathrm{C}$.

\begin{tabular}{|c|c|c|}
\hline \multirow[t]{2}{*}{$\begin{array}{l}\text { Mixture of black grass jelly } \\
\text { and encapsulants (stabilizer) }\end{array}$} & \multicolumn{2}{|c|}{$\begin{array}{c}\text { Cell count of } L \text {. plantarum } \\
\text { Mar8 }(\mathrm{CFU} / \mathrm{mL})\end{array}$} \\
\hline & Before stored & After stored \\
\hline Agar (1.5\%) & $9.7 \times 108$ & $18.8 \times 108$ \\
\hline Gum Arabic $(1.5 \%)$ & $6.7 \times 108$ & $9.5 \times 108$ \\
\hline
\end{tabular}

Changes in the characteristics of the jelly mixture with agar or gum Arabic are closely related to the differences from their properties. In order to be as "gelling agent", the higher the concentration, so the higher the "gelling" effect will be. Gum Arabic is more of an "emulsifier".

This study shows that at the concentrations up to $1 \%$, gum Arabic functions as stabilizer, but at the higher concentration gum Arabic functions more as an emulsifier. This is affecting breaking strength, so that the mixture becomes soft and flabby. Another consideration of the use of "gelling agent" is the compatibility of the $\mathrm{pH}$ and texture of the gelling agent itself. A typical jelly agent texture will indicate a good gelling agent. The criteria for a good jelly drink are soft gel texture so that when smoked to use the help of easy gel straws destroyed, but the shape of the gel is still felt in the mouth. Gel texture criteria for jelly drink this can be achieved by addition gelling agent in the jelly processing process drink (Vaniaa et al. 2017).

Syneresis is known to be influenced by several factors such as $\mathrm{pH}$, temperature, set pressure, and the properties of the chemical composition of the solvent (Aurand and Woods 1973; Costa et al. 2017). The $\mathrm{pH}$ value is also important to keep jelly drinks good for RTD drinks. At lower $\mathrm{pH}$ values, the rate of syneresis is increased because the gel becomes a higher ability of contractions (Jovanović et al. 2004).

Syneresis is an important factor to be considered because it is affecting the viability of encapsulated probiotics in the jelly. Probiotics encapsulations with agar or gum Arabic can maintain high viability of probiotics. The presence of probiotic cells with density reaching $10^{8}$ $10^{9} \mathrm{cfu} / \mathrm{mL}$ indicated that the probiotication has effectively functioned as a probiotic.

This study showed that the use of agar at a concentration of $0.5 \%$ or $1 \%$ was suitable for probiotication in jelly mixture, which indicated by its physical and organoleptic properties. This is agar has a hydroxyl group that is hydrophilic due to the nature of the agar which has a hydroxyl group that is hydrophilic. Therefore, agar has the ability to bind water strongly which result in the difficulty of water to evaporate (Widyaningsih and Safitri 2014). Another advantage of using agar result in increasing the total solids of the mixture. Moreover, its fillings can maintain a good texture of jelly (Widyaningsih and Safitri 2014).

The similar result also showed that the use of gum Arabic up to $1 \%$ was ideal for the use as the stabilizers of 
the Jelly and encapsulant of L. plantarum Mar8. This might be caused by its supporting characters as hydrocolloid (Bertolini et al. 2001; Rizqiati et al. 2009). Gum Arabic is recognized as an ordinary salt composed of calcium, magnesium and potassium ions (Prakash et al. 1990). Its hydrocolloid characteristic is very soluble in hot and cold water, so it will form a solution with low viscosity, but it is not soluble in alcohol and other organic solvents. The advantage of gum Arabic in food or drinks application was that it can retain the flavor of food dried by spray drying method because this gum can form layers that can protect flavor from oxidation, absorption, and evaporation (Bertolini et al. 2001). Because of its low viscosity, no taste and color, so adding gum Arabic in certain quantities does not interfere with the organoleptic properties of food products (Mosilhey 2003; Rizqiati et al. 2009).

It can be concluded that agar and gum Arabic can be used as an encapsulant that maintains high viability of probiotics and good stability. The concentration of $0.5 \%$ or $1 \%$ agar or gum Arabic were ideal or suitable for use both as the stabilizers and encapsulant of L. plantarum Mar8.

This study used a higher concentration of agar or gum Arabic for Lactobacillus's viability test rather than the suitable concentration (0.5-1\%) of those encapsulants. However, the result would be similar if that concentration was also applied. Rizqiati et al. (2009) reported that the use of gum Arabic was suitable for microencapsulation of $L$. plantarum. This study showed that agar or gum Arabic was supporting the probiotication as good encapsulant. Moreover, it was also suitable for stabilizing or gelling agent at $0.5 \%-1 \%$ concentration to produce black grass jelly as RTD.

Probiotication was successfully applied with ideal cell numbers $\left(\sim 10^{9} \mathrm{cfu} / \mathrm{mL}\right)$ so that this can be applied as probiotic for health food or drink supplement as RTD beverage. This study revealed a new upgrading of Jelly drinks to be healthier as RTD beverages by using suitable encapsulant to bring probiotication meet the prerequisites as probiotic for health supplement.

\section{ACKNOWLEDGEMENTS}

We thank Indonesia Ministry of Research, Technology and Higher Education for the Research Incentive National Innovation System (Insentif Riset Sistem Inovasi Nasional) activities with the title Functional Drinks for financial support and Research Center of Biology, Indonesian Institute of Sciences for research facilities. All authors have equally contributed.

\section{REFERENCES}

Anderson DMW, Eastwood MA. 1989. The safety of gum Arabic as a food additive and its energy value as an ingredient: a brief review. J Human Nutr Diet 2 (3): 137-144.

Aurand LW, Woods AE. 1973. Food Chemistry. Westport, Connecticut. The AVI Publishing Company Inc, New Delhi.

Bertolini AC, Siani AC, Grosso CRF. 2001. Stability of Monoterpenes encapsulated in gum Arabic by spray drying. J Agr Food Chem 49:780-785.
Booijink CC, Zoetendal EG, Kleerebezem M, de Vos WM. 2007. Microbial communities in the human small intestine: coupling diversity to metagenomics. Future Microbiol 2: 285-295.

Costa KK, Pertuzatti PB, Oliveira TF, Caliari M, Soares Junior MS. 2017. Syneresis and chemical characteristics of fermented rice extract with probiotic bacteria and waxy maize starch. Food Sci Technol 37 (4):640-646.

Elmanan M, Al-Assaf S, Phillips GO, Williams PA. 2008. Studies on Acacia exudate gums: Part VI. Interfacial rheology of Acacia senegal and Acacia seyal. Food Hydrocoll 22 (4): 682-689.

FAO/WHO. 2002. Guidelines for the evaluation of probiotics in food. Food and Agriculture Organization of the United Nations and World Health Organization Working Group Report.

Handayani D, Dewanti TW, Novita W, Hanifa MEH. 2017. Black grass jelly (Mesona palustris $\mathrm{Bl}$ ) effervescent powder has anti-dyslipidemia in high cholesterol diet-fed rats and antioxidant activity. Res J Life Sci 4 (3):2355-9926.

Jovanović S, Maćej O, Denin-Djurdjević J. 2004. Influence of selected factors on induced syneresis. J Agric Sci 49 (2): 205-217.

Latimer G. 2012. Official Methods of Analysis of AOAC International, 19th ed. AOAC, Gaithersburg, MD.

Maqbool M, Ali A, Alderson PG, Mohamed MTM, Siddiqui Y, Zahid N. 2011. Postharvest application of gum Arabic and essential oils for controlling anthracnose and quality of banana and papaya during cold storage. Postharvest Biol Technol 62 (1): 71-76.

Mosilhey SH. 2003. Influence of different capsule materials on the physiological properties of microencapsulated Lactobacillus acidophilus. Institute of Food Technology, Faculty of Agriculture, University of Bonn, Bonn.

Motlagh S, Ravines P, Karamallah KA, Ma Q. 2006. The analysis of Acacia gums using electrophoresis. Food Hydrocoll 20 (6): 848-854.

Mustafa MS, Chua SL, El-Enshasy AH, Majid AAF, Malek AR. 2016. A review on fruit juice probiotication: pomegranate. Curr Nutr Food Sci 12 (1): 4-11.

Nurhidayat N. 2012. Microencapsulation of probiotic Lactobacillus plantarum and analysis of its mannose-specific adhesin gene expression. Widyariset 15 (2).

O'Hara AM, Shanahan F. 2006. The gut flora as a forgotten organ. EMBO reports 7 (7): 688-693.

Prakash A, Joseph M, Manginon ME. 1990. The effects of added proteins on the functionality of gum arabic in soft drink emulsion systems. Food Hydrocoll 4 (3): 177-184.

Ramos SC, Fonseca FA, Kasmas SH, Moreira FT, Helfenstein T, Borges NC, Izar MC. 2011. The role of soluble fiber intake in patients under highly effective lipid-lowering therapy. Nutr J 10 (1): 10-80.

Rizqiati H, Jenie BSL, Nurhidayat N, Nurwitri CC. 2009. Characteristics of Lactobacillus plantarum probiotic microcapsules encapsulated with skim milk and gum arabic. J Indon Trop Anim Agric 34 (2): 139-144. [Indonesian]

Seddik HA, Bendali F, Gancel F, Fliss I, Spano G, Drider D. 2017. Lactobacillus plantarum and Its Probiotic and Food Potentialities. Probiotics Antimicrob Proteins 9: 111-122.

Tasia WRN, Widyaningsih TD. 2014. Potency of black grass jelly (Mesona palustris B1.), pandan leaves (Pandanus amaryllifolius) and cinnamon (Cinnamomum burmannii) as a raw material for herbal functional drink. Jurnal Pangan dan Agroindustri 2 (4): 128-136. [Indonesian]

Valiathan S, Athmaselvi KA. 2018. Gum Arabic based composite edible coating on green chilies. Int Agrophysics 32 (2):193-202.

Vania J, Utomo AR, Trisnawati CY. 2017. Effect of carrageenan concentration on the physicochemical and sensory properties of papaya jelly drink). J Food Technol Nutr 16 (1): 8-13.

Wahyono H, Fitriani L, Widyaningsih TD. 2015. Healthy potential of black grass jelly (Mesona palustris B1.) as functional foods: A review. Jurnal Pangan dan Agroindustri 3 (3): 957-961. [Indonesian]

Widyaningsih TD, Safitri RM. 2014. Anti-diarrhea effect of black grass jelly functional drink (Mesona palutris B1). Jurnal Agroteknologi 8 (1): 74-84. [Indonesian]

Yulianto RR, Widyaningsih TD. 2013. Formulation of herbal drink based on black grass jelly (Mesona palustris), ginger (Zingiber officinale) and Cinnamomum (Cinnamomum burmanii). Food Agroindustr J 1 (1): 65-77.

Yulinery T, Nurhidayat N. 2015. Antibacterial activity test of selected Lactobacillus plantarum isolated from Passiflora edulis related to plantaricin A (plnA) gene. Pros Sem Nas Masy Biodiv Indon 1: 270277. [Indonesian] 